\title{
Vascular damage effect of circulating microparticles in patients with ACS is aggravated by type 2 diabetes
}

\author{
XU-LAN WANG ${ }^{1}$, WEI ZHANG ${ }^{2},{\text { ZHE } \text { LI }^{2} \text {, WEN-QI HAN }}^{2}$, HAO-YU WU ${ }^{2}$, QUN-RANG WANG ${ }^{3}$, \\ XIN-HONG LIU ${ }^{2}$, KUN XING ${ }^{2}$, GONG CHENG $^{2}$ and FENG-JUN CHANG ${ }^{2}$ \\ ${ }^{1}$ Department of Nursing, Xian'yang Vocational and Technical College, Fengxi New Town United Avenue, Xi'an, \\ Shaanxi 712000; ${ }^{2}$ Department of Cardiology, Shaanxi Provincial People's Hospital and The Third Affiliated Hospital, \\ Xi'an Jiaotong University, Xi'an, Shaanxi 710068; ${ }^{3}$ Department of Cardiology, Affiliated Hospital of Shaanxi \\ Traditional Chinese Medicine University, Xianyang, Shaanxi 712000, P.R. China
}

Received February 28, 2020; Accepted November 3, 2020

DOI: $10.3892 / \mathrm{mmr} .2021 .12113$

\begin{abstract}
As a common factor of both type 2 diabetes mellitus (T2DM) and acute coronary syndrome (ACS), circulating microparticles (MPs) may provide a link between these two diseases. The present study compared the content and function of MPs from patients with ACS with or without T2DM. MPs from healthy subjects $(n=20)$, patients with ACS $(n=24)$, patients with T2DM $(n=20)$ and patients with combined ACS and T2DM $(n=24)$ were obtained. After incubating rat thoracic tissue with MPs, the effect of MPs on endothelial-dependent vasodilatation, expression of caveolin-1 and endothelial nitric oxide synthase (eNOS), phosphorylation of eNOS at the S1177 and T495 sites and its association with heat shock protein 90 (Hsp90), and the generation of NO and superoxide anion $\left(\mathrm{O}_{2}{ }^{-}-\right)$were determined. MP concentrations were higher in patients with T2DM and patients with ACS with or without T2DM than in healthy subjects. Moreover, MPs from patients with T2DM or ACS led to impairment in endothelial-dependent vasodilatation, decreased expression of NO, as well as eNOS and its phosphorylation at Ser1177 and association with Hsp90, but increased eNOS phosphorylation at T495, caveolin-1 expression and $\mathrm{O}_{2}{ }^{\circ}$ - generation. These effects were strengthened by MPs from patients with ACS combined with T2DM. T2DM not only increased MP content but also resulted in greater vascular impairment effects in ACS. These results may provide novel insight into the treatment of patients with ACS and T2DM.
\end{abstract}

Correspondence to: Dr Feng-Jun Chang or Dr Gong Cheng, Department of Cardiology, Shaanxi Provincial People's Hospital and The Third Affiliated Hospital, Xi'an Jiaotong University, 256 Friendship West Road, Xi'an, Shaanxi 710068, P.R. China

E-mail: mss0392@126.com

E-mail: xianchenggong@163.com

Key words: acute coronary syndrome, circulating microparticles, endothelial dysfunction, vascular injury

\section{Introduction}

Acute coronary syndrome (ACS) is characterized as a group of clinical syndromes caused by acute myocardial ischemia. ACS, which includes acute myocardial infarction and unstable angina, endangers lives and health (1). Studies have found that activation of platelets and impairment of endothelial function serve key roles in ACS occurrence $(2,3)$. Pathological changes caused by ACS are characterized by coronary atheromatous plaque rupture, inflammatory states, activated platelet adhesion/aggregation, vasospasm, thrombus formation and disability or even death $(4,5)$. Type 2 diabetes mellitus (T2DM), along with endothelial cell (EC) injury and coagulation activation, is considered to be a key element involved in the development of accelerated atherosclerosis (6-8). However, silent myocardial ischemia is a common feature in patients with ACS combined with T2DM due to damage to the nervous system caused by hyperglycemia (9). Therefore, it is important to identify indicator that may predict coronary artery damage in patients with T2DM. Circulating microparticles (MPs), which were previously considered to be cell waste, are primarily produced by injured ECs and activated platelets (10). However, a number of studies have revealed that MPs in pathological conditions can induce activation of coagulation and neutrophils, as well as vascular endothelial cell dysfunction or impairment (10-12). Our previous study demonstrated that the MP content increases in patients with ACS and that rising MP levels impair endothelial-dependent vasodilatation by inhibiting the AKT/endothelial nitric oxide synthase (eNOS)-heat shock protein (Hsp)90 signaling pathway (12). Thus, MPs are considered to be a marker of EC dysfunction and/or injury (13). Whether MPs participate in the influence of T2DM on coronary artery disease and their biological function remains unclear. The present study aimed to assess the effect of MPs from patients with ACS combined with T2DM on vasodilatation and endothelial function in rat thoracic aortas.

\section{Materials and methods}

Study population. Patients with ACS (without previous myocardialinfarction within 3 months) with ( $n=24$; age, $42.73 \pm 8$.46years; 12 male patients and 12 female patients) or without T2DM 
( $n=24$; age, $46.64 \pm 10.25$ years; 13 male patients and 11 female patients) and patients with T2DM $(n=20,45.36 \pm 11.81$ year, male/famale: 10/10) were recruited (Xi'an, China). Patients were recruited between March 2016 and September 2018. Patients with diseases that could increase MPs were excluded, including hypertension, renal failure, severe trauma, infectious disease, lupus anticoagulant, multiple sclerosis and rheumatic disease. For their influence on neurohumoral regulation, patients taking either angiotensin-converting enzyme inhibitors or angiotensin receptor blockers were excluded. Healthy subjects $(n=20$; age, 43.53 \pm 7.35 year; 11 male patients and 9 female patients), who were sex- and age-matched, were enrolled between June 2016 and December 2016 as volunteers. The present study was approved by The People's Hospital of Shaanxi Province Ethics Review Board. All participants signed informed consent forms.

Isolated MPs. Fasting peripheral blood from patients and healthy subjects was obtained on the initial hospitalization day. After centrifuging $\left(11,000 \mathrm{x} \mathrm{g} ; 2 \mathrm{~min} ; 4^{\circ} \mathrm{C}\right)$ the blood, platelet-poor plasma was obtained (50 $\mu \mathrm{l}$ was reserved for flow cytometric analysis). Then, the platelet-poor plasma was further centrifuged at $13,000 \mathrm{xg}$ for $45 \mathrm{~min}$ at $4^{\circ} \mathrm{C}$ as previously described (14). MPs precipitated in the bottom of the tube and were resuspended in $100 \mu 1$ RPMI-1640 medium (HyClone; Cytiva). A bicinchoninic acid protein assay (Merck Life Science UK, Ltd.) was used to assess the MP concentration. Before further analysis, MPs were stored at $-80^{\circ} \mathrm{C}$. Because limited blood samples could be obtained from each patient, isolated MPs from each group were mixed together for subsequent experiments. The time-points and concentrations of MPs used in the present study were as described in our previous study (15).

MP origin detection. The origin of MPs was detected by flow cytometric analysis. Following incubation of platelet-poor plasma with anti-CD31-PE (5 $\mu \mathrm{l}$; cat. no. 555027; 1:400; BD Biosciences) and anti-CD41-FITC ( $5 \mu \mathrm{l}$; cat. no. 561849; 1:400; BD Biosciences) for $30 \mathrm{~min}$ at $37^{\circ} \mathrm{C}$ as previously described (16), flow count calibrator beads (50 $\mu \mathrm{l}$; Beckman Coulter, Inc.) were added and incubated at $37^{\circ} \mathrm{C}$ for another $15 \mathrm{~min}$. Platelet-derived MPs [PMPs; CD31(+)/CD41(+)] and endothelial-derived MPs [EMPs; CD31(+)/CD41(-)] were counted and analyzed using an MoFlo XDP Cell Sorter (Beckman Coulter, Inc.; gate size, $<1 \mu \mathrm{m}$ ).

Vasodilatation study $(n=6)$. Sprague-Dawley male rats $(n=30$; age, 6 weeks; weight, $150 \pm 10 \mathrm{~g}$; purchased from the Central Laboratory of Shaanxi Provincial People's Hospital) were individually housed at $20 \pm 2^{\circ} \mathrm{C}$ with $55 \pm 10 \%$ humidity, 12:1 dark-light cycles, and free access to water and chow. Rats were decapitated following light anesthesia by pentobarbital (10 mg/kg; Sigma-Aldrich; Merck KGaA). The thoracic aorta was separated and cut into 3-5-mm segments [this process was conducted in ice-cold Krebs solution (Sigma-Aldrich; Merck KGaA)]. Tissue surrounding the aorta was removed. The aortic rings were then connected to an isometric force transducer (Emka Technologies) as previously described (15). Following equilibration in Krebs solution and continuous aeration $\left(95 \% \mathrm{O}_{2}\right.$ and $5 \% \mathrm{CO}_{2}$ ) for $1 \mathrm{~h}$ at $37^{\circ} \mathrm{C}$, aortic ring stabilization was tested by exposure to $60 \mathrm{mmol} / 1 \mathrm{KCl}$ for $2 \mathrm{~min}$ at $37^{\circ} \mathrm{C}$. Then, the rings were incubated with MPs $(2.5 \mathrm{mg} / \mathrm{ml})$ from all groups for $30 \mathrm{~min}$ at $37^{\circ} \mathrm{C}$. Phenylephrine (PE; $10^{-6} \mathrm{~mol} / \mathrm{l}$; Sigma-Aldrich;
Merck $\mathrm{KGaA}$ ) was added to pre-constrict the rings. Rings were incubated with the eNOS inhibitor NG-nitro-L-arginine methyl ester (L-NAME; $100 \mu \mathrm{mol} / 1$, Sigma-Aldrich; Merck KGaA) at $37^{\circ} \mathrm{C}$ for $30 \mathrm{~min}$. Time- and endothelium-dependent relaxation in response to acetylcholine $\left(10^{-8}-10^{-4} \mathrm{~mol} / \mathrm{l}\right.$; Sigma-Aldrich; Merck KGaA) was measured following PE pre-constriction. Briefly, following contraction to the maximum extent by $\mathrm{PE}$, different concentrations $\left(10^{-8}-10^{-4} \mathrm{~mol} / \mathrm{l}\right)$ of acetylcholine were added to dilate the blood vessels. The diastolic values of each acetylcholine concentration were recorded and analyzed. Similar to acetylcholine, endothelium-independent relaxation was tested using the nitrovasodilator sodium nitroprusside (SNP; $10^{-8}-10^{-4} \mathrm{~mol} / \mathrm{l}$; Sigma-Aldrich; Merck KGaA). Experiments were approved by The People's Hospital of Shaanxi Province Animal Ethics Committee. RPMI-1640 medium in the absence MPs was set as a blank control.

NO detection $(n=6)$. Vessel rings were opened longitudinally. Following equilibration at $37^{\circ} \mathrm{C}$ for $30 \mathrm{~min}$ in 48 -well plates with Krebs solution (Sigma-Aldrich; Merck KGaA), rings were incubated in the presence or absence of MPs $(2.5 \mathrm{mg} / \mathrm{ml})$ from each group for $1 \mathrm{~h}$ at $37^{\circ} \mathrm{C}$. Control groups were treated with an equal volume of RPMI-1640. Then, the rings were treated with diaminofluorescein diacetate $(10 \mu \mathrm{M}$; Sigma-Aldrich; Merck $\mathrm{KGaA}$ ) at $37^{\circ} \mathrm{C}$ for $30 \mathrm{~min}$. Vascular endothelial growth factor (50 ng/ml; Sigma-Aldrich; Merck KGaA) was added as a positive control. Laser scanning confocal microscopy (magnification, x200, emission, $515 \mathrm{~nm}$; excitation, $495 \mathrm{~nm}$ ) was used to obtain fluorescence images. Fluorescence intensity was assessed using ImageJ software (version 1.52; National Institutes of Health) as previously described (16). RPMI-1640 medium in the absence of MPs was set as a blank control.

Superoxide $\left(\mathrm{O}_{2}^{-}{ }^{-}\right)$detection $(n=6)$. First, the vessel rings were opened longitudinally. Following equilibration within Krebs solution for $30 \mathrm{~min}$ at $37^{\circ} \mathrm{C}$, the rings were treated in the presence or absence of L-NAME (1 mmol/l; Sigma-Aldrich; Merck $\mathrm{KGaA}$ ) at $37^{\circ} \mathrm{C}$ for $30 \mathrm{~min}$. Then, the rings were incubated in the presence or absence of MPs from all groups at $37^{\circ} \mathrm{C}$ for $30 \mathrm{~min}$. Next, the rings were incubated with hydroethidine (10 $\mu \mathrm{mol} / \mathrm{l}$; AnaSpec, Inc.) at $37^{\circ} \mathrm{C}$ for $30 \mathrm{~min}$. Fluorescence images were obtained by laser scanning confocal microscopy (magnification, x200; emission, $530 \mathrm{~nm}$; excitation, $488 \mathrm{~nm}$ ). $\mathrm{H}_{2} \mathrm{O}_{2}$ (0.5 mol/l; Sigma-Aldrich; Merck KGaA) was added as a positive control. Fluorescence intensity was assessed by ImageJ softwareas previously described (15). RPMI-1640 medium in the absence of MPs was set as a blank control.

Western blot analysis $(n=6)$. Following treatment in the presence or absence MPs from all groups at $37^{\circ} \mathrm{C}$ for $12 \mathrm{~h}$, the rat aortic proteins were obtained using RIPA lysis solution (Sigma-Aldrich; Merck KGaA). Protein concentrations were determined using a bicinchoninic acid protein assay. Proteins $(20 \mu \mathrm{g})$ were separated via SPS-PAGE (5\% concentrated gel and $8 \%$ separation gel) and transferred to PVDF membranes (Sigma-Aldrich; Merck KGaA). Following blocking with $5 \%$ skimmed milk powder (Sigma-Aldrich; Merck KGaA) at $37^{\circ} \mathrm{C}$ for $1 \mathrm{~h}$, the membranes were incubated with the following primary antibodies: eNOS (cat. no. sc-654; 1:1,000; Santa Cruz Biotechnology, Inc.), phosphorylated eNOS at T495 
Table I. Demographic, clinical and therapeutic characteristics of patients.

\begin{tabular}{|c|c|c|c|c|}
\hline Characteristic & Control $(n=20)$ & $\operatorname{ACS}(n=24)$ & T2DM $(n=20)$ & ACS with T2DM $(n=24)$ \\
\hline Age, years & $43.53 \pm 7.35$ & $46.64 \pm 10.25$ & $45.36 \pm 11.81$ & $42.73 \pm 8.46$ \\
\hline Sex, male/female & $11 / 9$ & $13 / 11$ & $10 / 10$ & $12 / 12$ \\
\hline Smoking & 6 & 11 & 10 & 11 \\
\hline Total cholesterol, mmol/l & $4.45 \pm 0.76$ & $5.96 \pm 0.95^{\mathrm{a}}$ & $5.77 \pm 0.58^{\mathrm{a}}$ & $6.12 \pm 0.89^{\mathrm{a}}$ \\
\hline Triglyceride, mmol/l & $0.97 \pm 0.42$ & $1.63 \pm 0.52^{\mathrm{a}}$ & $1.59 \pm 0.64^{\mathrm{a}}$ & $1.71 \pm 0.48^{\mathrm{a}}$ \\
\hline High density lipoprotein, mmol/1 & $1.15 \pm 0.37$ & $0.93 \pm 0.26^{\mathrm{a}}$ & $0.99 \pm 0.33^{\mathrm{a}}$ & $1.01 \pm 0.32^{\mathrm{a}}$ \\
\hline Low density lipoprotein, mmol/1 & $2.89 \pm 0.65$ & $3.67 \pm 0.61^{\mathrm{a}}$ & $3.48 \pm 0.75^{\mathrm{a}}$ & $3.89 \pm 0.58^{\mathrm{a}}$ \\
\hline Killip class, I/II/III/IV & 0/0/0/0 & $18 / 6 / 0 / 0^{\mathrm{a}}$ & $0 / 0 / 0 / 0$ & $16 / 8 / 0 / 0^{\mathrm{a}}$ \\
\hline \multicolumn{5}{|l|}{ Medication } \\
\hline$\beta$-receptor blockers & NA & $24^{\mathrm{a}}$ & $20^{\mathrm{a}}$ & $24^{\mathrm{a}}$ \\
\hline Nitrate esters & NA & $10^{\mathrm{a}}$ & 0 & $12^{\mathrm{a}}$ \\
\hline Anticoagulants & NA & $24^{\mathrm{a}}$ & $20^{\mathrm{a}}$ & $24^{\mathrm{a}}$ \\
\hline Hypoglycemics & NA & 0 & $20^{\mathrm{a}}$ & $24^{\mathrm{a}, \mathrm{b}}$ \\
\hline
\end{tabular}

Values are presented as the mean $\pm \mathrm{SD} .{ }^{a} \mathrm{P}<0.05$ vs. Control; ${ }^{\mathrm{b}} \mathrm{P}<0.05$ vs. ACS. ACS, acute coronary syndrome; T2DM, type 2 diabetes mellitus; NA, not applicable.

(cat. no. 9574; 1:800; Cell Signaling Technology, Inc.), phosphorylated eNOS at Ser1177 (cat. no. 9571; 1:800; Cell Signaling Technology, Inc.), caveolin-1 (cat. no. 3267; 1:10,000; Cell Signaling Technology, Inc.) and GAPDH (cat. no. 2118; 1:5,000, Cell Signaling Technology, Inc.) at $4^{\circ} \mathrm{C}$ for $12 \mathrm{~h}$. Subsequently, the membranes were incubated with horseradish peroxidase-conjugated secondary antibodies (cat. no. 7074S; Cell Signaling Technology, Inc.; equivalent dilution ratio to primary antibodies) at $37^{\circ} \mathrm{C}$ for $1 \mathrm{~h}$. Protein bands were visualized using enhanced chemiluminescence solution (cat. no. sc-2048; Santa Cruz Biotechnology, Inc.). Protein expression levels were semi-quantified using ImageJ software. RPMI-1640 medium in the absence of MPs was set as a blank control.

Immunoprecipitation $(n=6)$. Following treatment in the presence or absence of MPs from all groups for $12 \mathrm{~h}$ at $37^{\circ} \mathrm{C}$, aortic protein was harvested using RIPA lysis solution (Sigma-Aldrich; Merck KGaA). Protein concentrations were determined using a bicinchoninic acid protein assay. Subsequently, samples were treated with anti-eNOS antibody (cat.no.sc-136977; 1:1,000; Santa Cruz Biotechnology, Inc.) at $37^{\circ} \mathrm{C}$ for $24 \mathrm{~h}$ to immunoprecipitate eNOS. Then, the immunocomplex was mixed with Laemmli buffer (Sigma-Aldrich; Merck KGaA) and denatured $\left(95^{\circ} \mathrm{C}\right.$ for 5 min). After cooling on ice for $\geq 2 \mathrm{~min}$, protein was obtained by centrifugation $\left(680 \mathrm{x} \mathrm{g}, 2 \mathrm{~min}, 4^{\circ} \mathrm{C}\right)$. Then, immunoprecipitation of eNOS (cat. no. sc-654; 1:1,000; Santa Cruz Biotechnology, Inc.) and Hsp90 (cat. no. sc-13119; 1:1,000; Santa Cruz Biotechnology, Inc.) was tested as previously described (10). RPMI-1640 in the absence of MPs was set as a blank control.

Statistical analysis. Data are presented as the mean \pm SD. Data were analyzed using GraphPad Prism software (version 7.0; GraphPad Software, Inc.). Sex, smoking and medicine were compared by Chi-square test and Killip class was analyzed with Kruskal-Wallis test. Multigroup comparisons were tested by one-way analysis of variance followed by Bonferroni's

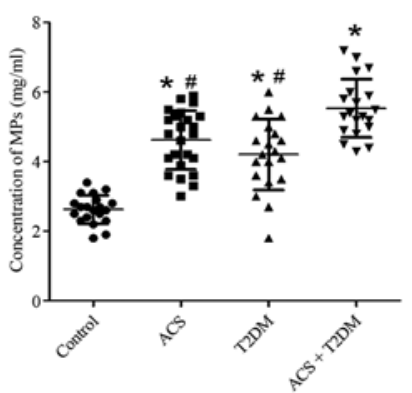

Figure 1. MP levels are increased in patients with ACS with or without T2DM. MPs were increased in patients with ACS $(4.63 \pm 0.86 \mathrm{mg} / \mathrm{ml}$; $\mathrm{n}=24)$ and T2DM $(4.21 \pm 0.77 \mathrm{mg} / \mathrm{ml} ; \mathrm{n}=20)$ compared with the Control $(2.84 \pm 0.69 \mathrm{mg} / \mathrm{ml} ; \mathrm{n}=20)$. MP content was further increased in patients with both ACS and T2DM $(5.54 \pm 0.73 \mathrm{mg} / \mathrm{ml}, \mathrm{n}=24)$. Data are presented as the mean \pm SD. ${ }^{*} \mathrm{P}<0.05$ vs. Control; ${ }^{\#} \mathrm{P}<0.05$ vs. ACS+T2DM. MP, microparticle; ACS, acute coronary syndrome; T2DM, type 2 diabetes mellitus.

multiple comparison post hoc test. $\mathrm{P}<0.05$ was considered to indicate a statistically significant difference.

\section{Results}

Clinical data. There were no differences in characteristics (sex and age) between controls and patients except for lipids and medications (Table I).

MP concentrations. Compared with the control $(2.84 \pm 0.69 \mathrm{mg} / \mathrm{ml})$, MPs concentrations were increased in patients with ACS $(4.63 \pm 0.86 \mathrm{mg} / \mathrm{ml})$ and T2DM $(4.21 \pm 0.77 \mathrm{mg} / \mathrm{ml})$. MP levels $(5.54 \pm 0.73 \mathrm{mg} / \mathrm{ml})$ were further increased in patients with both ACS and T2DM (Fig. 1).

MP origins. Compared with the control, patients with ACS or T2DM exhibited higher proportions of EMPs $(32.9 \pm 7.3$ and $33.9 \pm 4.2$ vs. $20.2 \pm 4.3 \%$, respectively) and PMPs (28.8 \pm 6.4 and $29.9 \pm 5.1$ vs. $22.0 \pm 6.2 \%$, respectively; Fig. 2). The proportions 
A

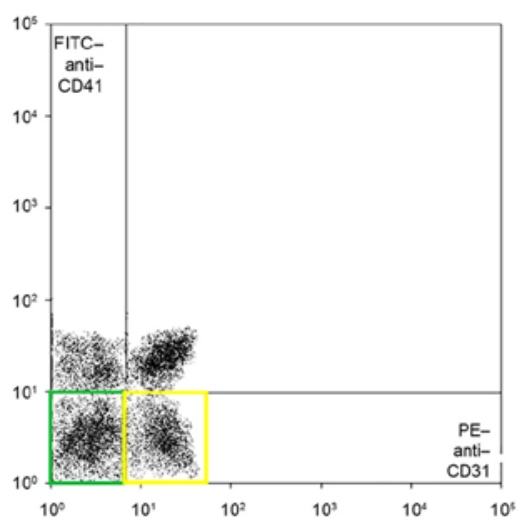

B

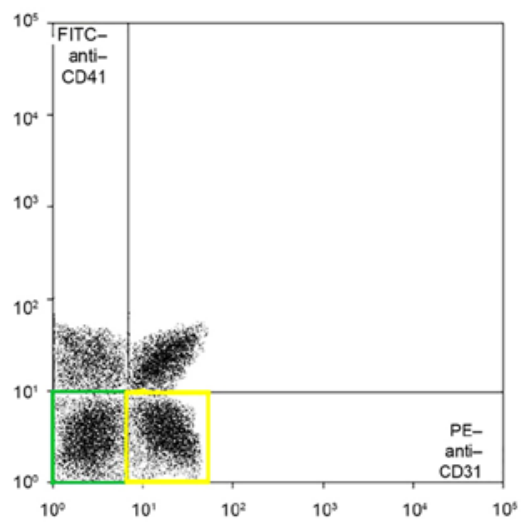

E

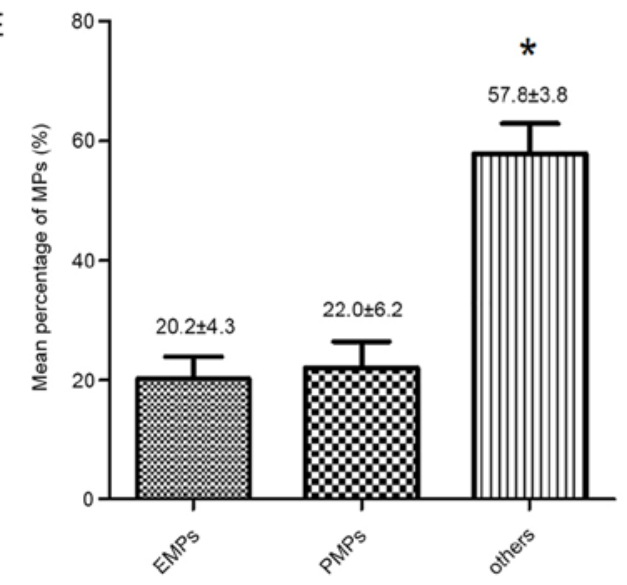

F

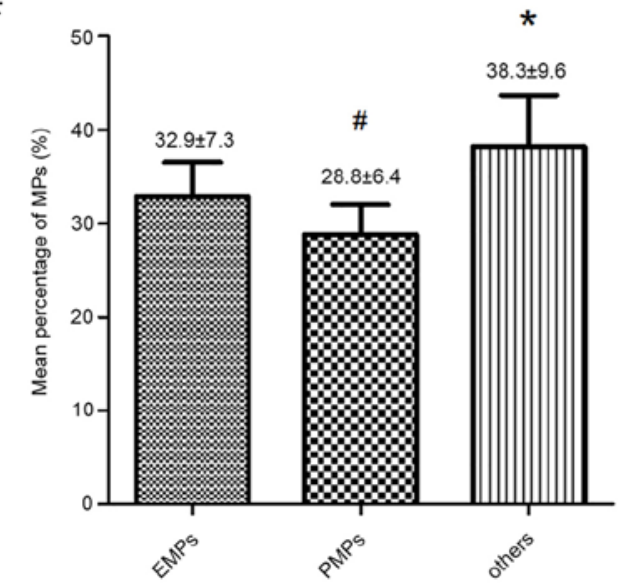

C

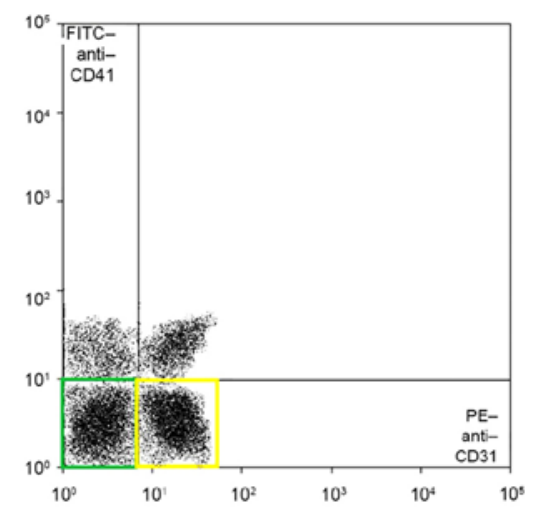

D

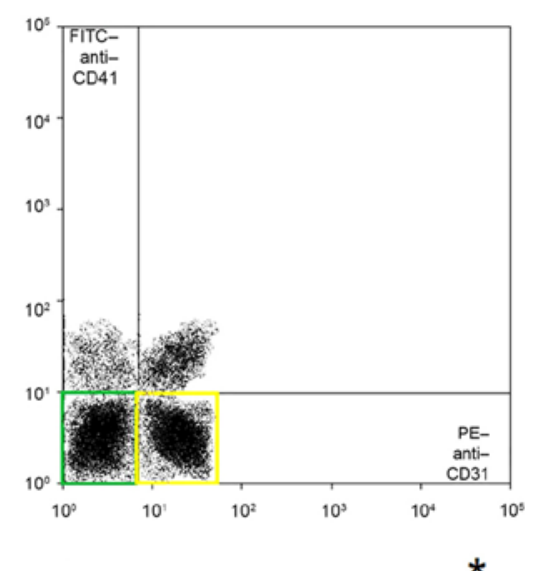

G

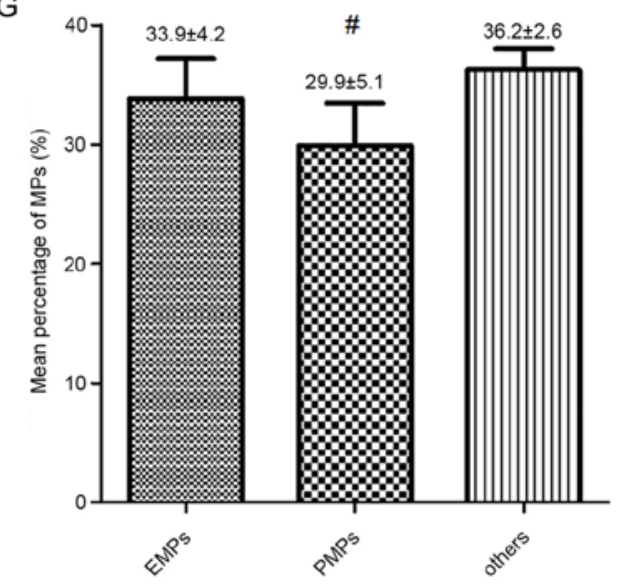

$\mathrm{H}$

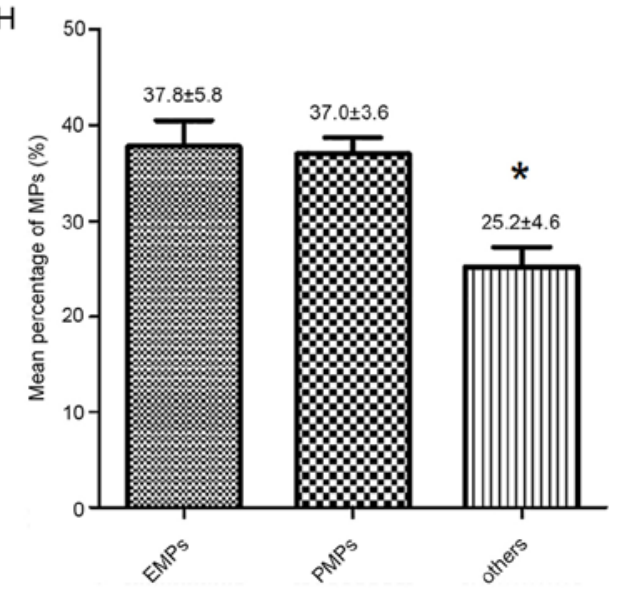

Figure 2. MP origin detection. Compared with the Control (A and B), both EMPs [CD31(+)/CD41(-); yellow; 20.2 $\pm 4.3 \%]$ and PMPs [(CD31(+)/CD41(+); green; $22.0 \pm 6.2 \%]$ increased in patients with ACS (C and D); EMPs 32.9 $\pm .3 \%$; PMPs $28.8 \pm 6.4 \%, \mathrm{n}=24$ ) and patients with T2DM (E and F); EMPs $33.9 \pm 4.2 \%$; PMPs $29.9 \pm 5.1 \%, \mathrm{n}=24)$; the EMP and PMP content was further increased in patients with ACS concurrent with T2DM (G and H); EMPs 37.8 $\pm 5.8 \%$; PMPs $37.0 \pm 3.6 \%$; $\mathrm{n}=20$ ). ${ }^{*} \mathrm{P}<0.05$ vs. EMPs and PMPs; ${ }^{\text {} P}<0.05$ vs. EMPs. MP, microparticle; EMP, endothelial-derived MP; PMP, platelet-derived MP; ACS, acute coronary syndrome; T2DM, type 2 diabetes mellitus. 
A

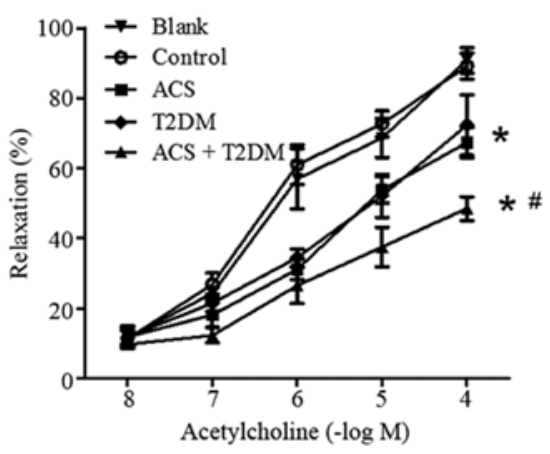

B

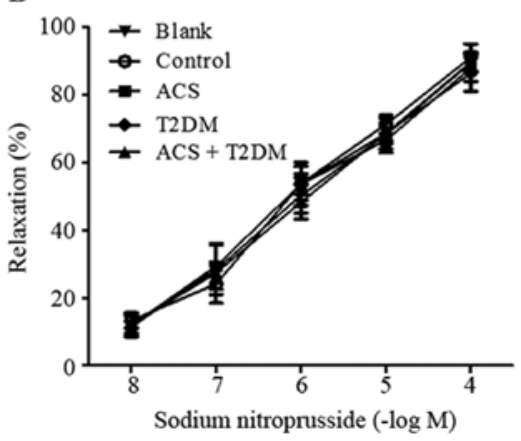

Figure 3. Effects of MPs from patients with ACS concurrent with T2DM on endothelium-dependent and -independent dilatation. (A) Compared with the Control, MPs ( $3 \mathrm{mg} / \mathrm{ml})$ from patients with ACS or T2DM impaired endothelium-dependent dilatation stimulated by acetylcholine. MPs from patients with ACS concurrent with T2DM further decreased endothelium-dependent dilatation. (B) There were no differences in endothelium-independent vasodilator responses to sodium nitroprusside between MPs from Controls and patients with ACS and/or T2DM. Data are presented as the mean \pm SD ${ }^{*} \mathrm{P}<0.05$ vs. the Control; ${ }^{\prime} \mathrm{P}<0.05$ vs. ACS, T2DM. MP, microparticle; ACS, acute coronary syndrome; T2DM, type 2 diabetes mellitus.

of EMPs $(37.8 \pm 5.8 \%)$ and PMPs $(37.0 \pm 3.6 \%)$ in patients with ACS concurrent with T2DM were significantly increased compared with all other groups (Fig. 2D and H).

Effect of MPs on vasodilatation. Compared with the control, MPs from patients with ACS or T2DM impaired endothelium-dependent relaxation (Fig. 3A). This effect was strengthened by MPs from patients with ACS concurrent with T2DM (Fig. 3A). However, endothelium-independent vasodilatation response to SNP was unaltered by MPs from all groups (Fig. 3B).

Effects of MPs on $\mathrm{NO}$ and $\mathrm{O}_{2} \cdot$ - generation. Compared with the control group, MPs from patients with ACS or T2DM increased $\mathrm{O}_{2}{ }^{\circ}$ - generation (Fig. 4) but decreased NO (Fig. 5) production. The influence on both $\mathrm{NO}$ and $\mathrm{O}_{2}{ }^{\circ}$ - generation was enhanced by MPs from patients with ACS concurrent with T2DM (Figs. 4 and 5). However, the increased $\mathrm{O}_{2}{ }^{\circ}-$ in patients with ACS concurrent with T2DM was partly blocked by L-NAME (Fig. 4).

Effects of MP on eNOS and caveolin-1 expression levels. Western blotting was used to investigate the mechanism by which MPs affect endothelial function. Compared with the control group, MPs from patients with ACS or T2DM decreased eNOS and its phosphorylation at the Ser1177 site

(Fig. 6A) but increased caveolin-1 (Fig. 7A) and eNOS phosphorylation at the T495 site (Fig. 6B). These effects were strengthened by MPs from patients with ACS concurrent with T2DM (Figs. 6 and 7A).

Effects of MPs on immunoprecipitation. Immunoprecipitation was performed to detect the effect of MPs on the association of eNOS with Hsp90. MPs from patients with ACS or T2DM decreased the association of eNOS with Hsp90; MPs from patients with ACS concurrent with T2DM further enhanced these effects (Fig. 7B).

\section{Discussion}

The present study indicated that MPs increased in patients with ACS with or without T2DM. MPs from patients with ACS, particularly those with concurrent T2DM, impaired endothelium-dependent vasodilatation, increased $\mathrm{O}_{2}{ }^{\circ}$ - production, caveolin-1 expression and eNOS phosphorylation at T495 but decreased NO generation, eNOS and its phosphorylation at Ser1177, and uncoupled the association between eNOS and Hsp90 in the rat aorta.

Relatively low levels of MPs exist in healthy subjects. However, numerous studies have reported that increased MPs are found in a number of diseases associated with the vascular system (17-20). Our previous study (12) revealed that MPs are increased in patients with ACS; this impairs vasodilatation by uncoupling the correlation of eNOS with Hsp90, inhibiting the eNOS-Hsp90 pathway and Hsp90 and increasing oxidative stress. Biasucci et al (21) reported that MPs are further increased in ACS compared with stable angina (SA) but MP levels are not positively correlated with the atherosclerotic burden of patients with SA. Bernal-Mizrachi et al (22) determined that a high number of EMPs was associated with lesions with thrombi, multiple irregular lesions and eccentric type II lesions. Mild to moderate (but not severe) stenosis is associated with increasing EMP levels, which indicates that EMP may be a useful marker of endothelial dysfunction. The present study demonstrated that increasing MPs are further increased in patients with both ACS and T2DM compared with ACS-alone.

Oxidative stress, inflammation and endothelial dysfunction have been reported in T2DM $(23,24)$. As a key etiological factor and therapeutic target of vascular complications in T2DM, endothelial dysfunction may also be associated with diseases with vascular complications (25-28). In order to investigate the overlap of T2DM and MPs in the circulatory system, the present study examined whether T2DM could further enhance the effects of MPs on endothelial dysfunction.

Vasodilatation, which is primarily regulated by NO, serves a key role in hemoperfusion regulation (29). Wong et al (26) reported that specific therapies targeting increased eNOS activity may decrease morbidity and mortality ofcardiovascular diseases related to diabetes and hypertension by reversing endothelial dysfunction. Our previous study (12) indicated that MPs from patients with ACS impaired endothelial-dependent vasodilatation via the AKT/eNOS-Hsp90 pathway. In the present study, MPs from patients with both ACS and T2DM induced greater impairment of endothelium-dependent vasodilatation by blocking eNOS and its phosphorylation at Ser1177, 


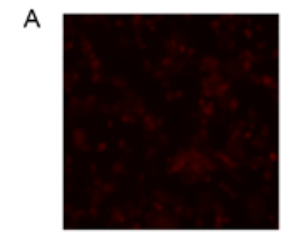

blank

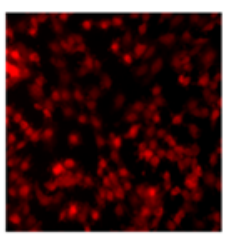

ACS

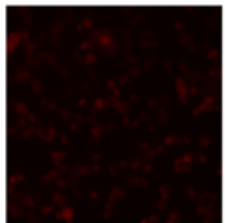

control

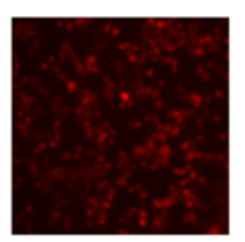

T2DM

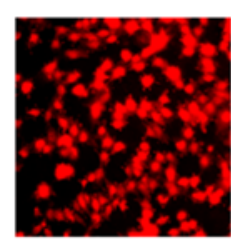

ACS+T2DM

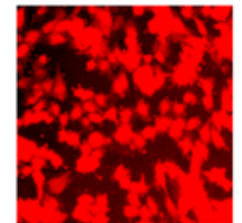

$\mathrm{H}_{2} \mathrm{O}_{2}$

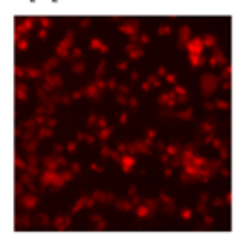

ACS+T2DM+L-NAM

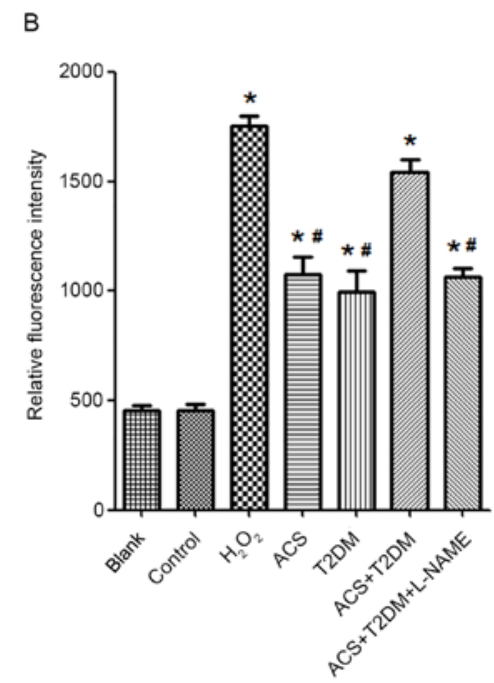

Figure 4. Effects of MPs from patients with ACS concurrent with T2DM on $\mathrm{O}_{2}{ }^{-}$- generation. (A) MPs from patients with ACS or T2DM increased $\mathrm{O}_{2}{ }^{-}-$production; this was enhanced by MPs from patients with ACS concurrent with T2DM but partly blocked by L-NAME (n=6). Magnification, x200. (B) Relative fluorescence intensity. ${ }^{\mathrm{P}}<0.05$ vs. Blank and Control; ${ }^{\#} \mathrm{P}<0.05$ vs. ACS + T2DM. MP, microparticle; ACS, acute coronary syndrome; T2DM, type 2 diabetes mellitus; L-NAME, NG-nitro-L-arginine methyl ester.

A

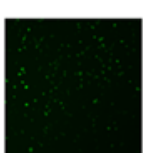

Blank

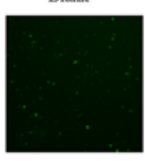

ACS

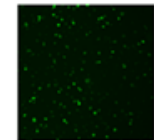

Control

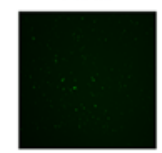

T2DM

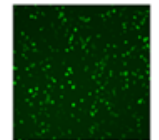

VEGF
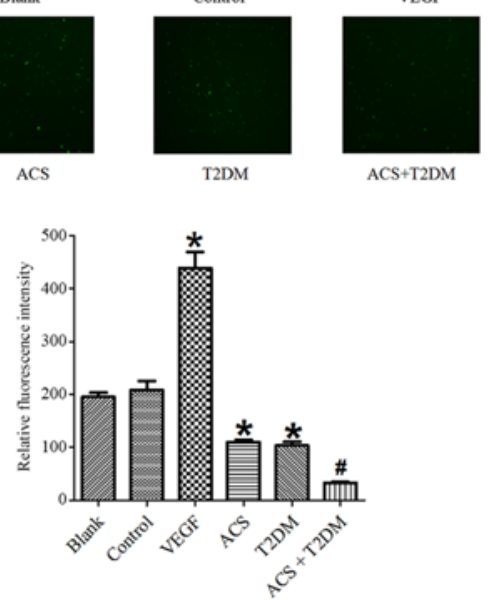

Figure 5. Effects of MPs from patients with ACS concurrent with T2DM on NO generation. (A) MPs from patients with ACS and/or T2DM decreased NO production. Magnification, $\mathrm{x} 200$. (B) Relative fluorescence intensity. ${ }^{*} \mathrm{P}<0.05$ vs. Blank, Control; ${ }^{\#} \mathrm{P}<0.05$ vs. ACS, T2DM. MP, microparticle; ACS, acute coronary syndrome; T2DM, type 2 diabetes mellitus. thus strengthening the expression of eNOS phosphorylation at T495.

As a structural caveolin protein, caveolin-1 decreases $\mathrm{NO}$ generation by interacting with eNOS $(30,31)$. Meye et al (32) revealed that homocysteine affected the association of eNOS with caveolin-1, which results in endothelial dysfunction and decreased NO generation. Qin et al (33) reported that hypercholesterolemia impairs NO production and may participate in atherosclerosis by promoting eNOS association with caveolin-1. Zhao et al (34) revealed that mice deficient in the caveolin-1 gene exhibited significantly higher NO levels. The present study indicated that MPs from patients with ACS, particularly those with concurrent T2DM, upregulated expression of caveolin-1. This may participate in the impairment of both vasodilatation and $\mathrm{NO}$ production.

An imbalance between the production of vasoconstricting and vasodilating (e.g. NO) factors plays a key role in atherosclerosis. NO offsets reactive oxygen species (35). eNOS-derived NO serves a key role in the regulation of vessel inflammatory status and tone (36). The primary mechanism underlying the imbalance between $\mathrm{NO}$ and $\mathrm{O}_{2}^{-}$- is eNOS uncoupling (12). Thus, the present study determined whether MPs from patients with ACS and/or T2DM could affect oxidative stress and the 
A
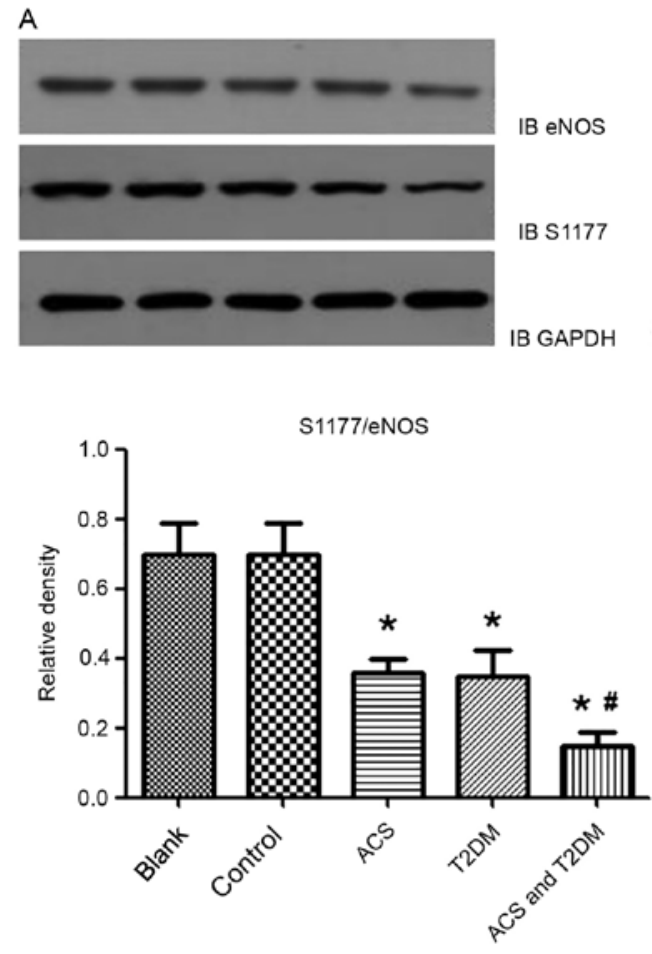

eNOS/GAPDH

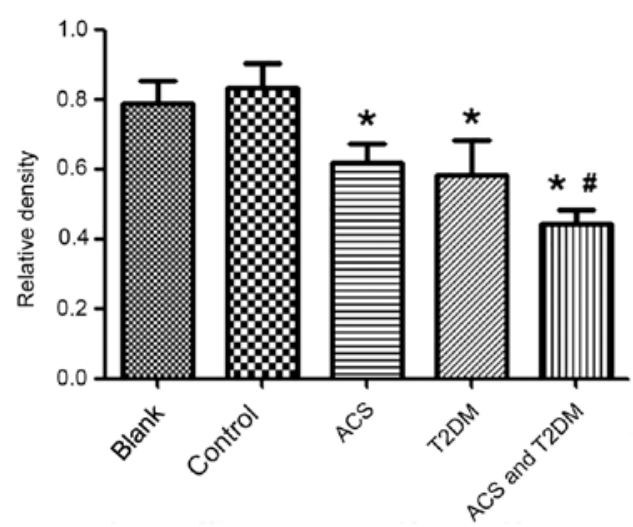

B

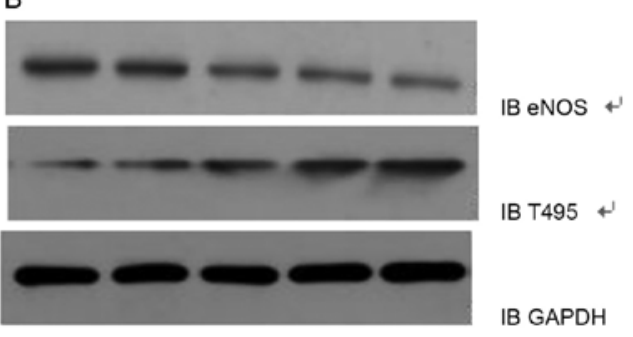

T495/eNOS

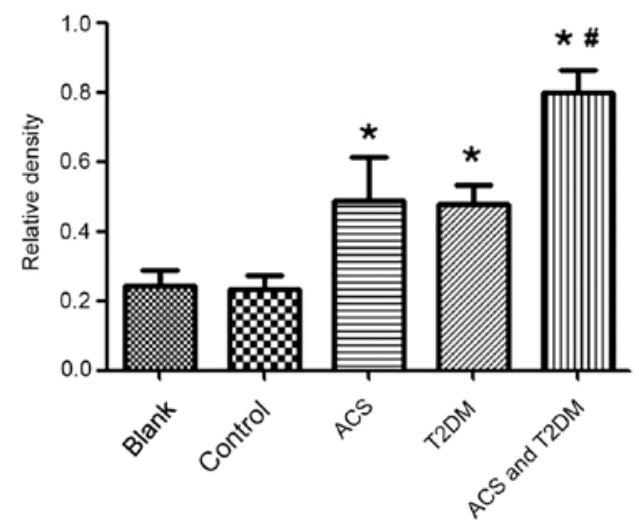

eNOS/GAPDH

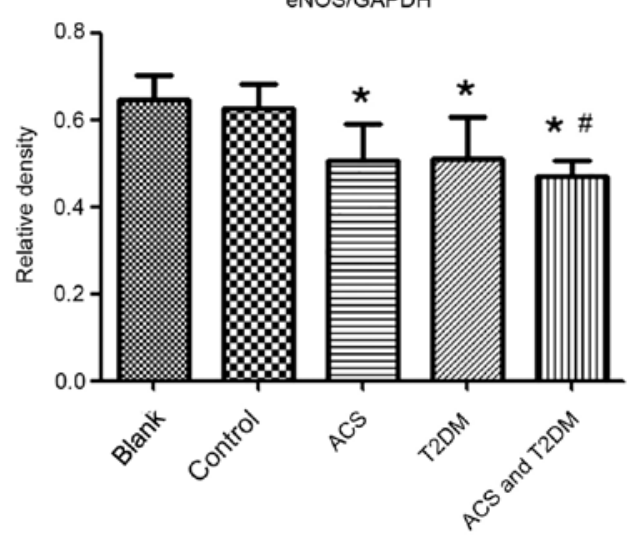

Figure 6. Effects of MPs from patients with ACS concurrent with T2DM on eNOS in the rat thoracic aorta. MPs from patients with ACS and/or T2DM (A) decreased eNOS and its phosphorylation at the Ser1177 site and (B) upregulated eNOS phosphorylation at T495 in the rat thoracic aorta. "P<0.05 vs. Blank and Control; ${ }^{\text {"P }}<0.05$ vs. ACS and T2DM. MP, microparticle; ACS, acute coronary syndrome; T2DM, type 2 diabetes mellitus; eNOS, endothelial nitric oxide synthase.
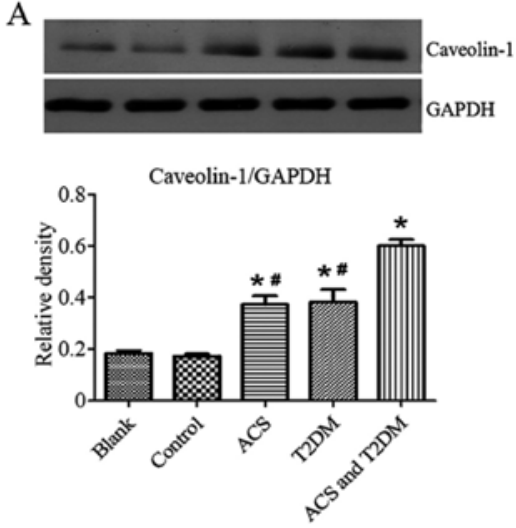

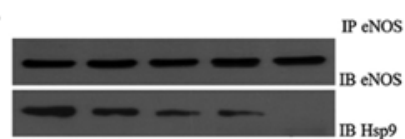

Hsp90/eNOS

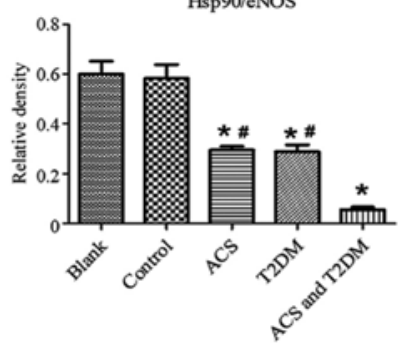

Figure 7. Effects of MPs from patients with ACS concurrent with T2DM on caveolin-1 expression and the association of eNOS with Hsp90 in rat thoracic aorta. Compared with the Control, MPs from patients with ACS and/or T2DM (A) significantly increased caveolin-1 expression and (B) decreased the association between eNOS and Hsp90. ${ }^{*} \mathrm{P}<0.05$ vs. Blank and Control; ${ }^{\text {}} \mathrm{P}<0.05$ vs. ACS and T2DM. MP, microparticle; ACS, acute coronary syndrome; T2DM, type 2 diabetes mellitus; eNOS, endothelial nitric oxide synthase; Hsp90, heat shock protein 90. 
association of eNOS with Hsp90. MPs from patients with ACS, particularly those with concurrent T2DM, decreased NO generation and the amount of eNOS that associated with $\mathrm{Hsp} 90$ but increased $\mathrm{O}_{2}{ }^{-}$- production. In addition, the increased $\mathrm{O}_{2}{ }^{-}$- was blocked by L-NAME. These data indicated that MPs increased oxidative stress by eNOS uncoupling.

The present study used a mixture of MPs of different origins, as it was not possible to isolate EMPs and PMPs from human blood. Rats are often used in cardiovascular pharmacology research and screening of novel drugs due to their responsiveness (indicated by changes in blood pressure and vascular resistance). However, differences between the aorta of SD rats and humans means experiments must be performed on human aortic endothelial cells to verify the present results. In addition, future research should use a larger sample size and include classification of ACS (e.g. unstable angina, acute ST/non-ST segment elevation myocardial infarction).

In summary, MPs from patients with both ACS and T2DM further enhanced the effects of MPs from patients with ACS on endothelial-dependent vasodilatation by decreasing eNOS, its phosphorylation at Ser1177 and association with Hsp90 and $\mathrm{NO}$ production and increasing caveolin-1 expression, $\mathrm{O}_{2}{ }^{\circ}-$ generation and eNOS phosphorylation at T495. These results confirmed that MPs may be a useful marker of endothelial dysfunction.

\section{Acknowledgements}

Not applicable.

\section{Funding}

No funding was received.

\section{Availability of data and materials}

The datasets used and/or analyzed during the current study are available from the corresponding author on reasonable request.

\section{Authors' contributions}

FJC conceptualized and designed the study. XLW and FJC performed the experiments, and drafted and revised the manuscript. WZ, ZL and HYW collected, analyzed and interpreted data. WQH, QRW and GC performed the experiments, and drafted and revised the manuscript. XHL, KX and GC conceived the study and provided final approval of the version to be published. FJC, XLW and GC confirm the authenticity of all the raw data. All authors read and approved the final manuscript.

\section{Ethics approval and consent to participate}

The present study was approved by The People's Hospital of Shaanxi Province Ethics Review Board. All participants signed informed consent forms. Experiments involving animals were approved by The People's Hospital of Shaanxi Province Animal Ethics Committee.

\section{Patient consent for publication}

Not applicable.

\section{Competing interests}

The authors declare that they have no competing interests.

\section{References}

1. Gach O, El HZ and Lancellotti P: Acute coronary syndrome. Rev Med Liege 73: 243-250, 2018 (In French).

2. .Wang R, Wang M, Ye J, Sun G and Sun X: Mechanism overview and target mining of atherosclerosis: Endothelial cell injury in atherosclerosis is regulated by glycolysis (Review). Int $\mathbf{J}$ Mol Med 47: 65-76, 2021.

3. Libby P, Ridker PM and Maseri A: Inflammation and atherosclerosis. Circulation 105: 1135-1143, 2002.

4. Kristensen SD, Ravn HB and Falk E: Insights into the pathophysiology of unstable coronary artery disease. Am J Cardiol 80: 5E-9E, 1997.

5. Freedman JE and Loscalzo J: Nitric oxide and its relationship to thrombotic disorders. J Thromb Haemost 1: 1183-1188, 2003.

6. McGuire DK, Emanuelsson H, Granger CB, E Magnus Ohman, D J Moliterno, H D White, D Ardissino, J W Box, R M Califf and E J Topol: Influence of diabetes mellitus on clinical outcomes across the spectrum of acute coronary syndromes. Findings from the GUSTO-IIb study. GUSTO IIb Investigators. Eur Heart J 21: 1750-1758, 2000.

7. Hildebrandt P: Diabetic patients and acute coronary syndromes. Eur Heart J 22: 887-888, 2001.

8. Han D, Rozanski A, Gransar H, Sharir T, Einstein AJ, Fish MB, Ruddy TD, Kaufmann PA, Sinusas AJ, Miller EJ, et al: Myocardial ischemic burden and differences in prognosis among patients with and without diabetes: Results from the multicenter international REFINE SPECT registry. Diabetes Care 43: 453-459, 2020.

9. Wackers FJ, Young LH, Inzucchi SE, Chyun DA, Davey JA, Barrett EJ, Taillefer R, Wittlin SD, Heller GV, Filipchuk N, et al: Detection of silent myocardial ischemia in asymptomatic diabetic subjects: The DIAD study. Diabetes Care 27: 1954-1961, 2004.

10. Martinez MC, Tesse A, Zobairi F and Andriantsitohaina R: Shed membrane microparticles from circulating and vascular cells in regulating vascular function. Am J Physiol Heart Circ Physiol 288: H1004-H1009, 2005.

11. Zaldivia MTK, McFadyen JD, Lim B, Wang X and Peter K: Platelet-derived microvesicles in cardiovascular diseases. Front Cardiovasc Med 4: 74, 2017.

12. Han WQ, Chang FJ, Wang QR and Pan JQ: Microparticles from patients with acute coronary syndrome impair vasodilatation by inhibiting the Akt/eNOS-Hsp90 signaling pathway. Cardiology 132: 252-260, 2015.

13. Koga H, Sugiyama S, Kugiyama K, Watanabe K, Fukushima H, Tanaka T, Sakamoto T, Yoshimura M, Jinnouchi H and Ogawa H: Elevated levels of VE-cadherin-positive endothelial microparticles in patients with type 2 diabetes mellitus and coronary artery disease. J Am Coll Cardiol 45: 1622-1630, 2005.

14. Boulanger CM, Scoazec A, Ebrahimian T, Henry P, Mathieu E, Tedgui A and Mallat Z: Circulating microparticles from patients with myocardial infarction cause endothelial dysfunction. Circulation 104: 2649-2652, 2001.

15. Cheng G, Shan XF, Wang XL, Dong WW, Li Z, Liu XH, Zhang W, Xing K and Chang FJ: Endothelial damage effects of circulating microparticles from patients with stable angina are reduced by aspirin through ERK/p38 MAPKs pathways. Cardiovase Ther 35: 2017.

16. Ci HB, Ou ZJ, Chang FJ, Liu DH, He GW, Xu Z, Yuan HY, Wang ZP, Zhang $X$ and Ou JS: Endothelial microparticles increase in mitral valve disease and impair mitral valve endothelial function. Am J Physiol Endocrinol Metab 304: E695-E702, 2013.

17. Wen B, Combes V, Bonhoure A, Weksler BB, Couraud PO and Grau GE: Endotoxin-induced monocytic microparticles have contrasting effects on endothelial inflammatory responses. PLoS One 9: e91597, 2014. 
18. Colle IO, De Vriese AS, Van Vlierberghe HR, Lameire NH and De Vos MM: Vascular hyporesponsiveness in the mesenteric artery of anaesthetized rats with cirrhosis and portal hypertension: An in-vivo study. Eur J Gastroenterol Hepatol 16: 139-145, 2004.

19. Erol A and Koşay S: Effects of aminoguanidine administration on vascular hyporeactivity in thoracic aorta from endotoxaemic rats. Eur J Pharmacol 408: 175-181, 2000.

20. Martin S, Tesse A, Hugel B, Martínez MC, Morel O, Freyssinet JM and Andriantsitohaina R: Shed membrane particles from T lymphocytes impair endothelial function and regulate endothelial protein expression. Circulation 109: 1653-1659, 2004.

21. Biasucci LM, Porto I, Di Vito L, De Maria GL, Leone AM, Tinelli G, Tritarelli A, Di Rocco G, Snider F, Capogrossi MC and Crea F: Differences in microparticle release in patients with acute coronary syndrome and stable angina. Circ J 76: 2174-2182, 2012.

22. Bernal-Mizrachi L, Jy W, Fierro C, Macdonough R, Velazques HA, Purow J, Jimenez JJ, Horstman LL, Ferreira A, de Marchena E and Ahn YS: Endothelial microparticles correlate with high-risk angiographic lesions in acute coronary syndromes. Int J Cardiol 97: 439-446, 2004.

23. Hu FB and Stampfer MJ: Is type 2 diabetes mellitus a vascular condition? Arterioscler Thromb Vasc Biol 23: 1715-1716, 2003.

24. Ceriello A and Motz E: Is oxidative stress the pathogenic mechanism underlying insulin resistance, diabetes, and cardiovascular disease? The common soil hypothesis revisited. Arterioscler Thromb Vasc Biol 24: 816-823, 2004.

25. Tang X, Luo YX, Chen HZ and Liu DP: Mitochondria, endothelial cell function, and vascular diseases. Front Physiol 5: 175, 2014.

26. Wong WT, Wong SL, Tian XY and Huang Y: Endothelial dysfunction: The common consequence in diabetes and hypertension. J Cardiovasc Pharmacol 55: 300-307, 2010.

27. Wang F, Guo X, Shen X, Kream RM, Mantione KJ and Stefano GB: Vascular dysfunction associated with type 2 diabetes and Alzheimer's disease: A potential etiological linkage. Med Sci Monit Basic Res 20: 118-129, 2014.
28. Münzel T: Endothelial dysfunction: Pathophysiology, diagnosis and prognosis. Dtsch Med Wochenschr 133: 2465-2470, 2008 (In German).

29. Tejero J, Shiva S and Gladwin MT: Sources of vascular nitric oxide and reactive oxygen species and their regulation. Physiol Rev 99: 311-379, 2019.

30. Voldstedlund M, Vinten J and Tranum-Jensen J: Cav-p60 expression in rat muscle tissues. Distribution of caveolar proteins. Cell Tissue Res 306: 265-276, 2001.

31. Mineo C and Shaul PW: Regulation of eNOS in caveolae. Adv Exp Med Biol 729: 51-62, 2012.

32. Meye C, Schumann J, Wagner A and Gross P: Effects of homocysteine on the levels of caveolin-1 and eNOS in caveolae of human coronary artery endothelial cells. Atherosclerosis 190: 256-263, 2007.

33. Qin L, Zhu N, Ao BX, Liu C, Shi YN, Du K, Chen JX, Zheng XL and Liao DF: Caveolae and caveolin-1 integrate reverse cholesterol transport and inflammation in atherosclerosis. Int J Mol Sci 17: 429, 2016

34. Zhao YY, Liu Y, Stan RV, Fan L, Gu Y, Dalton N, Chu PH, Peterson K, Ross J Jr and Chien KR: Defects in caveolin-1 cause dilated cardiomyopathy and pulmonary hypertension in knockout mice. Proc Natl Acad Sci USA 99: 11375-11380, 2002.

35. Pechánová $\mathrm{O}$ and Simko $\mathrm{F}$ : The role of nitric oxide in the maintenance of vasoactive balance. Physiol Res 2 (Suppl 56): S7-S16, 2007.

36. Yetik-Anacak G and Catravas JD: Nitric oxide and the endothelium: History and impact on cardiovascular disease. Vascul Pharmacol 45: 268-276, 2006.

This work is licensed under a Creative Commons Attribution-NonCommercial-NoDerivatives 4.0 International (CC BY-NC-ND 4.0) License. 